\title{
Emergency general surgery 'Hot Clinics' reduce admission rates and duration of inpatient stay
}

\author{
Francesca Th'ng, ${ }^{1}$ Christos Skouras, ${ }^{1}$ Alice Paterson-Brown, ${ }^{2}$ \\ Rajan Ravindran, ${ }^{3}$ Peter Lamb, ${ }^{3}$ Andrew de Beaux, ${ }^{3}$ \\ Simon Paterson-Brown, ${ }^{3}$ Damian J Mole, ${ }^{1,3}$ on behalf of the Edinburgh \\ Emergency Surgery Study Group
}

\begin{abstract}
- Additional material is published online only. To view, please visit the journal online (http://dx.doi.org/10.1136/ flgastro-2015-100634).
\end{abstract}

For numbered affiliations see end of article.

\section{Correspondence to} Francesca Th'ng, Department of Surgery, Royal Infirmary of Edinburgh, 51 Little France Crescent, Edinburgh EH16 4SA, UK; fcsthng1@doctors.org.uk

Previous communications: International Surgical Congress of the Association of Surgeons of Great Britain and Ireland (ASGBI) 2015, Manchester, UK. Oral presentation as Short Pape on 23rd April 2015. Session: T3C3 General Surgery/Surgical pathways ASGBI Short Papers 12. Presentation unique code 448. Abstract reference: Th'ng $F$ Skouras C, Lamb P, et al. Impact of Hot Clinic on acute general surgical admissions. BJS

2015;102(Suppl 7):63.

Received 1 August 2015 Revised 5 November 2015 Accepted 10 November 2015 Published Online First

14 December 2015

\section{CrossMark}

\footnotetext{
To cite: Th'ng F, Skouras C, Paterson-Brown $\mathrm{A}$, et al. Frontline Gastroenterology 2017:8:53-61.
}

\begin{abstract}
Objective To determine the impact of a 'Hot Clinic' (HC) on emergency general surgery patient flow-through.
\end{abstract}

Design Prospective service evaluation study. Setting $\mathrm{HC}$ is a four-bedded area coordinated by a specialist nurse. The HC consultant sees emergency patients referred from the emergency department, general practitioners or those in preceding $24 \mathrm{~h}$ considered suitable for interim discharge while awaiting investigations and $\mathrm{HC}$ reassessment.

Patients All patients with acute abdominal pain were evaluated in three 4 week groups: before (group 1), 1 month (group 2) and 6 months after the HC was introduced (group 3). Interhospital transfers, intrahospital ward referrals and trauma patients were excluded.

Intervention Introduction of consultant-led surgical HC every weekday afternoon.

Main outcome measures Proportion of patients admitted under general surgeons, length of inpatient stay and the proportion of patients referred again within 3 months were investigated.

Results 1409 patients were referred, of which 1061 met the inclusion criteria: 307 in group 1, 326 in group 2 and 428 in group 3 . There was no difference in gender distribution ( $p=0.759$ ). Inpatient admissions were significantly reduced $(85.0 \%$ vs $78.2 \%$ vs $54.4 \% ; p<0.001)$ and the inpatient duration of stay was significantly shorter after $\mathrm{HC}$ introduction (median (IQR) (95\% CI) 63.8 (29.0-111.6) (51.8 to 72.8 ) hours vs $48.8(21.7-101.2)$ (42.0 to 55.6 ) hours vs 47.7 (20.9-92.7) (42.8 to 56.9) hours; $\mathrm{p}=0.011$ ). Conclusions Emergency general surgery HCs are associated with significant reductions in admission rates and inpatient bed occupancy. This service redesign has the potential to dramatically relieve pressure on acute surgical services.

\section{INTRODUCTION}

Acute abdominal pain is the most common reason for referral to an emergency general surgery service, accounting for approximately $1 \%$ of all hospital admissions, $10 \%$ of referrals to the emergency departments (EDs) and 50\% of all emergency admissions under general surgery in the UK. ${ }^{1-3}$ In Scotland, there has been an increase of $>30 \%$ $(n=36329)$ in the admission rate of all general surgical (excluding vascular) patients since $2011,{ }^{4}$ resulting in a significant strain on National Health Service (NHS) resources both clinically and financially. In an effort to adapt to this resource-intensive increased demand, a consultant-led surgical Hot Clinic (HC) was introduced at the Royal Infirmary of Edinburgh (RIE). The specific aims of the HC were to identify those patients who could be safely and effectively managed as 'outpatients' and to streamline the care of those in need of inpatient surgical treatment by the early involvement of senior surgical decision-makers.

All other disciplines in Medicine are facing similar challenges due to increasing demand. A range of strategies have been adopted nationally to address the challenge, for example, the coordination of the Ambulatory Emergency Care coordinated alongside the $\mathrm{ED},{ }^{5}$ and a consultant-led phone triage system put into place in NHS Derby Hospitals. These strategies have been successful in reducing overall hospital admissions and 
improving the patient experience. ${ }^{5} 6$ Communitybased consultation and patient care have also been initiated in several regions. ${ }^{7} 8$ For example, the 'House of Care' service model has been introduced by NHS England Trusts, ${ }^{9}$ and the Rapid Elderly Assessment Care Team (REACT) ${ }^{10}$ has been initiated in NHS Lothian.

Similarly, strategies to overcome the increasing demand on the general surgical services have also been proposed. The setting up of an ambulatory surgical HC by other hospitals has shown promise. In one study, introduction of a HC demonstrated a significant reduction in time patients waited to be seen by a doctor and in the proportion of patients being admitted. ${ }^{11}$ That study concluded that the HC is cost-effective and improves the efficiency of surgical services. In a separate context, the efficient and effective services provided in an ambulatory $\mathrm{HC}$ were well received by patients. ${ }^{12}$

We devised and introduced the HC to streamline the care pathway of patients referred for acute surgical assessment. The aim of the present study was to evaluate the impact of the HC on patient flow, specifically examining the proportion of patients with acute abdominal pain admitted under general surgery and the time then spent as an inpatient for those in need of admission.

\section{METHODS}

\section{General surgical unit}

The RIE is a major acute teaching hospital within NHS Lothian. There are 900 inpatient beds. The General Surgery Department in RIE consists of two inpatient wards, one Surgical Observation Unit which includes an Assessment Unit (for the HC) and a Day Surgery Unit. There are 85 general surgical inpatient beds. The General Surgery Department in the RIE cares for adults and teenagers aged 13 years and older. In NHS Lothian, approximately $11 \%$ of ED attendances are surgically related. ${ }^{13}$ In 2013/2014, there were 25645 general surgery episodes (excluding vascular surgery) throughout NHS Lothian, of which $42 \%$ ( $n=10858$ episodes) were recorded as emergency inpatients. ${ }^{4}$ There is a dedicated emergency theatre fully staffed $24 \mathrm{~h}$ a day, 7 days a week for general and vascular patients. The general surgery emergency on-call team is led by one consultant from Monday to Sunday with overnight support from a second consultant surgeon.

\section{The HC}

The HC is an area within the Surgical Observation Unit adjacent to the ED with four beds allocated exclusively for surgical assessment. It is coordinated by a specialist nurse practitioner and is staffed by the on-call lead emergency consultant surgeon supported by the rostered emergency team surgical trainees every weekday afternoon between 13:00 and 17:00, Monday-Friday. During this HC period, an additional consultant surgeon is rostered to cover the emergency operating theatre with the on-call registrar. This represents five additional consultant surgeon sessions. The main purpose of the $\mathrm{HC}$ is to ensure efficient assessment and management of surgical patients while preventing and reducing unnecessary admissions.

During the HC, the responsible consultant is based in the surgical receiving unit and reviews patients referred by the general practitioner or from the ED as they present. Patients presenting to the hospital at any time of the day or night (ie, outwith the HC period) can be sent home to return to this 'review' session. Referral to the HC can be made by any doctor or allied healthcare practitioner. All referrals are triaged by a member of the on-call surgical team. To ensure the efficient running of the $\mathrm{HC}$, the Radiology Department agreed to fast-track requests for ultrasound scans and CT, performing them either the same afternoon or the following day.

\section{Pilot study}

A pilot study for the HC was carried out before its formal introduction. This study was carried out for 3 weeks, two with the $\mathrm{HC}$ and one without, during which questionnaires (see online supplementary appendix 1) were distributed to patients and surgical staff. The qualitative results (see online supplementary appendix 2) of this pilot study informed subsequent study design. The pilot study demonstrated that the average time elapsing between being referred to the surgical team and being seen by a trainee (Foundation doctor or medical student) was $46 \mathrm{~min}$ and the average time elapsing between the patient being seen by a surgical trainee and the consultant was $24 \mathrm{~min}$. This pilot study ultimately supported the introduction of the $\mathrm{HC}$ and informed the design of the main study. This study also demonstrated that $30 \%$ of all patients assessed during the week were seen during the Monday-Friday HC period.

\section{Study approval}

This study was assessed by the South East Scotland Research Ethics Service of NHS Lothian and was declared exempt from ethical review under the terms of the Governance Arrangements for Research Ethics Committees (Harmonised Edition). Caldicott Guardian consent was obtained to allow the use of confidential patient data.

\section{Study design}

This is a prospective service evaluation study carried out in a formative approach with three study groups -one before the introduction of the $\mathrm{HC}$ and two at defined intervals thereafter.

\section{Inclusion and exclusion criteria}

All patients referred to the on-call general surgeons with acute abdominal pain, irrespective of age and 
nature of pain, were included. Patients transferred from other hospitals, obstetric and trauma patients, patients who were already admitted under a different specialty (ward referrals) and patients with other nonabdominal acute surgical conditions were excluded from the present study.

\section{Patients and data collection}

The data collection period was for four calendar weeks in each group, that is, 12 weeks in total. The study timeline is presented in figure 1A. Four weeks was chosen as the period for data collection for each group as this provided a sufficient and representative sample size based on the pilot study data. Group 1 consists of patients who were referred with acute abdominal pain during the 4 weeks prior to the introduction of the HC, from 2 June 2014 to 29 June 2014. After the introduction of the HC, a 4-week 'bedding-in' phase was initiated prior to the enrolment of group 2 patients from 28 July 2014 to 24 August 2014. An 18-week 'consolidation' interval was allowed prior to the enrolment of group 3 patients (28 December 2014 to 24 January 2015). Eligible subjects were identified through daily handover sheets, and from the emergency team admission and discharged patient electronic lists. Patient data were collected from the national electronic patient record (TRAK) system.

\section{Definitions}

The length of ARU stay was defined as the period between the time of presentation (the time that the patient arrived in the ARU) and the time of discharge or transfer into a hospital bed. Inpatient length of stay (LOS) was calculated in hours from the time of ED discharge to the time each patient was discharged from the general surgery ward. Patients who were reviewed by a member of the surgical team and for whom it was decided that admission under general surgery was inappropriate, and who were instead admitted under a different specialty were considered to have been discharged from surgical care. They have been included in the calculation of the proportion of patients being admitted as part of the denominator, but have not been included in the calculation of the duration of stays. Patients in all three groups were followed up for 3 months from the date of their index presentation. If they were referred again for surgical review within this time frame with symptoms similar to those of their index presentation, they were considered either 're-presentations' or 're-admissions' as illustrated in figure $1 \mathrm{~B}$.

\section{Statistical analysis}

The main outcome variables of interest were the duration of inpatient stay, the proportion of patients admitted and the proportions referred again. Continuous variables are presented as a median and IQR. Categorical variables are presented as absolute and relative frequencies. The Pearson $\chi^{2}$ test was used to examine the association between categorical variables. The Kolmogorov-Smirnov test was used to compare the distribution of data against the Normal
A

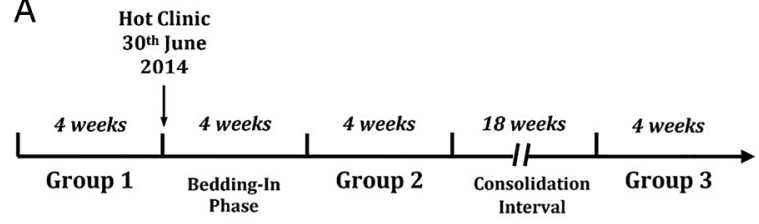

B

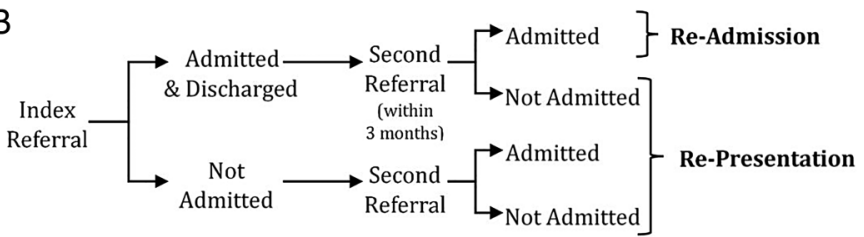

C

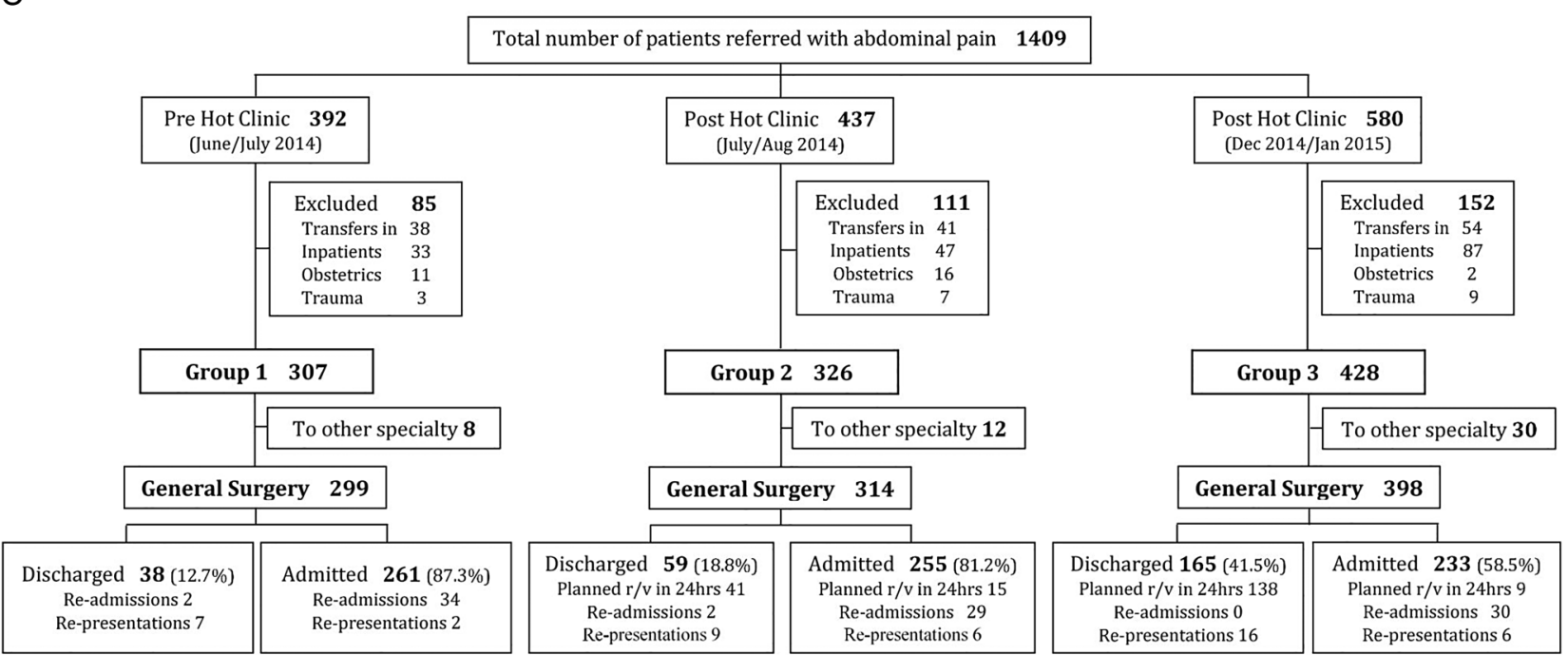

Figure 1 (A) Timeline of the study. (B) Definitions of readmission/re-presentation. 
distribution. The Kruskal-Wallis test was used to compare non-parametric variables and later the Mann-Whitney $U$ test if a significant difference was present. Post-hoc calculated power of the difference in admission rates between groups 1 and 3 using a twotailed $\mathrm{z}$ test with significance $\alpha=0.05$ was 1.000 with a critical $\mathrm{z}$ value of 1.959. All statistical tests were based on a two-sided $\alpha$-value of 0.05 . Statistical analysis was performed using IBM SPSS Statistics V.19.0 (IBM, Armonk, New York, USA) and G*Power V.3.1 (Universität Düsseldorf, Germany).

\section{RESULTS}

\section{Study population}

A total of 1409 consecutive patients were referred to the surgical on-call team over the three study periods of which $1061(75.3 \%)$ were included in the study. There were 307 patients in study group 1 (29.0\%), 326 $(30.7 \%)$ in group 2 and $428(40.3 \%)$ in group 3. The care pathway of all patients is shown in the CONSORT diagram in figure 1C. There were no missing data for any of the variables of interest for all three groups. The demographics of the patients are shown in table 1 . Patients in group 3 were significantly younger than those of group 1 (median: 44.1 years, IQR: 26.459.7 years vs median 48.7 years, IQR: $30.3-67.1$ years; Mann-Whitney U test, $1 \mathrm{df}, \mathrm{p}=0.003)$. Non-specific abdominal pain (NSAP) was the most common diagnosis in all three groups (table 2).

\section{Inpatient admissions}

Introduction of the HC was associated with a significant reduction in the proportion of general surgery patients being admitted as inpatients: group 1: 261/ 307 (85.0\%), group 2: 255/326 (78.2\%) and group 3: $233 / 428(54.4 \%)\left(\chi^{2}\right.$ test, $\left.2 \mathrm{df}, \mathrm{p}<0.001\right)$ (table 1$)$. This significant difference was also seen when group 3 was compared with both group 1 and group 2 in $2 \times 2$ contingency tables $\left(\chi^{2}\right.$ test, $\left.1 \mathrm{df}, \mathrm{p}<0.001\right)$. There was no statistical difference in the age and gender of patients being admitted in all three groups.

\section{Length of inpatient stay}

The introduction of the $\mathrm{HC}$ was associated with a significant reduction in the inpatient LOS between the three groups: group 1: median (IQR) 63.77 (28.98111.58) hours; group 248.83 (21.67-101.22); group 3: $47.72(20.87-92.67)\left(\chi^{2}\right.$ test, $\left.2 \mathrm{df}, \mathrm{p}=0.011\right)$, see figure 2. This significant difference was seen between group 1 and group 2 in a $2 \times 2$ contingency table $\left(\chi^{2}\right.$ test, $1 \mathrm{df}, \mathrm{p}=0.022)$ and between group 1 and group 3 ( $\chi^{2}$ test, $\left.1 \mathrm{df}, \mathrm{p}=0.005\right)$. The significant reduction of inpatient stay between groups 1 and 3 by $16.1 \mathrm{~h}$ translates to a reduction of $25 \%(16.1 / 63.77 \mathrm{~h})$ in inpatient bed occupancy. Both mirror diagrams in figure 2 demonstrate an increased percentage of patients being discharged within $48 \mathrm{~h}$ of being admitted under the general surgeons in group 2 and group
3 in comparison with group 1 . There was no significant difference in the age and gender distribution of patients staying $>48 \mathrm{~h}$ between the three groups.

\section{Re-referrals (readmissions and re-presentations)}

There was an apparent reduction of $2 \%$ in the proportion of patients being referred again to the surgical team for presenting symptoms similar to those of the index referral, although this was not statistically significant $(p=0.723)$ (table 1). There was also a reduction of $4.5 \%$ in the proportion of patients being readmitted between group 1 and group 3 . There was no difference in age (Kruskal-Wallis test, $2 \mathrm{df}$, $\mathrm{p}=0.791)$, gender $\left(\chi^{2}\right.$ test, $\left.2 \mathrm{df}, \mathrm{p}=0.610\right)$ and diagnosis (most commonly diagnosis of NSAP in all three groups) ( $p=0.365$ ) of patients being referred again in all three groups.

\section{Planned reviews in $\mathbf{2 4} \mathrm{h}$}

A total of 203 patients from both group 2 and group 3 were discharged with a planned surgical review $24 \mathrm{~h}$ later. These patients were significantly younger (median: 33.6 years, IQR: $23.4-48.8$ years; $\mathrm{p}<0.001$ ), female $(154 / 203,75.9 \%$; $p<0.001)$ and had a diagnosis of NSAP $(132 / 203,65.0 \% ; \mathrm{p}<0.001)$.

\section{DISCUSSION}

Over the past decades, the number of emergency general surgery admissions has been increasing steadily and shows no sign of reaching a plateau. This is a nationwide problem that needs to be addressed rapidly and efficiently. ${ }^{4}{ }^{14-16}$ There is clearly a pressing need to optimise the efficiency of acute surgical services. The present study has demonstrated that the introduction of a general surgery HC significantly reduced the proportion of patients with acute abdominal pain admitted as inpatients and the duration of inpatient LOS.

Strengths of the study include the type of design-a formative approach was taken and hence the study evaluated the impact of the HC and allowed for feedback to be implemented. For example, the study informed the Department on the possible improvements in patient recording prior to re-collection of group 3 data. The study period was spread out to take a realistic account of the possible different phases in a service redesign and the better results in group 3 demonstrated that a 'bedding in' time was required. The pilot study provided important qualitative data and helped inform the design of the study.

In another study, ${ }^{17}$ the length of inpatient hospital stay for general surgery patients was shown to be associated with age. This can mainly be explained by the increased burden of comorbidities in this population and their prolonged admission for social reasons. ${ }^{18}$ In this study, group 3 patients were significantly younger than those in group 1, but the inpatient LOS in group 3 compared with group 1 was not statistically 
Table 1 Patient demographics of the study groups

\begin{tabular}{|c|c|c|c|c|c|}
\hline N (\%) & $\begin{array}{l}\text { Overall sample } \\
1061\end{array}$ & $\begin{array}{l}\text { Group } 1 \\
307 / 1061(29.0 \%)\end{array}$ & $\begin{array}{l}\text { Group } 2 \\
326 / 1061(30.7 \%)\end{array}$ & $\begin{array}{l}\text { Group } 3 \\
428 / 1061(40.3 \%)\end{array}$ & $\mathrm{p}$ Value \\
\hline \multicolumn{6}{|l|}{ Gender* (ratio, \%) } \\
\hline Male & $368 / 1061(34.7)$ & 110/307 (35.8) & 108/326 (33.1) & $150 / 428(35.0)$ & \multirow[t]{2}{*}{0.759} \\
\hline Female & $693 / 1061(65.3)$ & 197/307 (64.2) & $218 / 326(66.9)$ & $278 / 428(65.0)$ & \\
\hline \multicolumn{6}{|l|}{ Age (years)* } \\
\hline Median & 45.7 & 48.7 & 45.7 & 44.1 & \multirow[t]{3}{*}{$0.009 \ddagger$} \\
\hline IQR & $28.2-63.2$ & $30.3-67.1$ & $29.5-62.9$ & $26.4-59.7$ & \\
\hline $95 \% \mathrm{Cl}$ & 43.2 to 47.5 & 43.2 to 51.9 & 41.7 to 48.6 & 40.5 to 47.0 & \\
\hline \multicolumn{5}{|l|}{ Admission into general surgery* } & \multirow[t]{4}{*}{$<0.001 \dagger$} \\
\hline Ratio, \% & 749/1061 (70.6) & $261 / 307(85.0)$ & 255/326 (78.2) & $233 / 428(54.4)$ & \\
\hline \multirow{3}{*}{\multicolumn{6}{|c|}{$\begin{array}{l}\text { Discharged"* } \\
\text { Ratio, \% } \\
\text { Planned review in } 24 \mathrm{~h}^{*}\end{array}$}} \\
\hline & & & & & \\
\hline & & & & & \\
\hline Ratio, \% & 203/1061 (19.1) & Not applicable & $56 / 326(17.2)$ & $147 / 428(34.3)$ & $<0.001 \dagger$ \\
\hline \multicolumn{6}{|l|}{ ARU LOS§ (h) } \\
\hline Median & 3.57 & 3.57 & 3.55 & 3.57 & \multirow[t]{3}{*}{0.977} \\
\hline IQR & $3.0-3.95$ & $3.10-3.93$ & $3.02-3.95$ & $2.82-3.98$ & \\
\hline $95 \% \mathrm{Cl}$ & 3.50 to 3.63 & 3.45 to 3.67 & 3.45 to 3.68 & 3.50 to 3.72 & \\
\hline \multicolumn{6}{|l|}{ Inpatient LOS§ (h) } \\
\hline Median & 51.68 & 63.77 & 48.83 & 47.72 & \multirow[t]{3}{*}{$0.011=$} \\
\hline IQR & 23.17-102.37 & $28.98-111.58$ & 21.67-101.22 & $20.87-92.67$ & \\
\hline $95 \% \mathrm{Cl}$ & 47.72 to 57.05 & 51.75 to 72.78 & 420.2 to 55.62 & 42.80 to 56.90 & \\
\hline \multicolumn{6}{|l|}{ USS§ (ratio, \%) } \\
\hline No & $445 / 1011(44.0)$ & $140 / 299(46.8)$ & 125/314 (39.8) & $180 / 398(45.2)$ & \multirow[t]{2}{*}{0.178} \\
\hline Yes & $566 / 1011(56.0)$ & $159 / 299(53.2)$ & 189/314 (60.2) & 218/398 (54.8) & \\
\hline \multicolumn{6}{|l|}{ CT§ (ratio, \%) } \\
\hline No & 769/1011 (76.1) & 233/299 (77.9) & 236/314 (75.2) & $300 / 398(75.4)$ & \multirow[t]{2}{*}{0.666} \\
\hline Yes & $242 / 1011(23.9)$ & $66 / 299(22.1)$ & $78 / 314(24.8)$ & $98 / 398(24.6)$ & \\
\hline \multicolumn{6}{|l|}{ MRCP§ (ratio, \%) } \\
\hline No & $902 / 1011(89.2)$ & 256/299 (85.6) & 277/314 (88.2) & $369 / 398(92.7)$ & \multirow[t]{2}{*}{$0.009 t$} \\
\hline Yes & $109 / 1011(10.8)$ & 43/299 (14.4) & $37 / 314(11.8)$ & 29/398 (7.3) & \\
\hline Total re-referrals (ratio, \%) & & $45 / 299(15.1)$ & $46 / 314(14.6)$ & $52 / 398(13.1)$ & $0.723+$ \\
\hline Re-presentations & & $9 / 299(3.0)$ & 15/314 (4.8) & $22 / 398(5.5)$ & $0.280 \dagger$ \\
\hline Readmissions & & $36 / 299(12.0)$ & $31 / 314(9.9)$ & $30 / 398(7.5)$ & $0.133 \dagger$ \\
\hline
\end{tabular}

${ }^{*}$ Comparison with all patients within the SG.

†Pearson $\chi^{2}$ test (asymptotic significance, two-sided).

$\ddagger$ Kruskal-Wallis test for independent samples.

$\S$ Comparison with only general surgical patients within the SG (excluding 'To other specialty').

LOS, length of stay.

significant. Moreover, there was no significant difference in the age of patients staying for $>48 \mathrm{~h}$ as inpatients in all the groups. Hence, it would appear that the reduction in the inpatient LOS is independent of age in this study. Previous studies involving general surgery patients presenting with acute abdominal pain in the UK have consistently shown a predominance of the diagnosis of NSAP. ${ }^{19} 20$ The incidence of NSAP in the present study (approximately 39\%) is comparable with other reports (34.9\% ${ }^{19}$ and $36 \%,{ }^{20}$ respectively). This would suggest that this study's patient sample is representative of the UK.

The introduction of the HC to the general surgical services is an effective service redesign. The management of patients presenting with an acute abdomen often requires further monitoring and repeated clinical assessments and/or laboratory and imaging investigations. The $\mathrm{HC}$ allows the management of such selected patients in an ambulatory out-of-hospital fashion while still receiving the required assessments and/or investigations within $24 \mathrm{~h}$. Patient management plans are made sooner because decision-making in the $\mathrm{HC}$ is by a senior surgeon. Collaboration with the Radiology department and prioritising imaging requests are essential and enabled the HC to run effectively and efficiently. These management factors therefore reflect on the significant reduction in hospital LOS. Five additional 
Table 2 Discharge diagnoses of all general surgical patients

\begin{tabular}{|c|c|c|c|c|}
\hline Diagnosis & $\begin{array}{l}\text { Group } 1 \\
\text { (Pre-HC) } \\
(n=299)(\%)\end{array}$ & $\begin{array}{l}\text { Group } 2 \\
\text { (1 month post-HC) } \\
(\mathrm{n}=314)(\%)\end{array}$ & $\begin{array}{l}\text { Group } 3 \\
\text { (6 months post-HC) } \\
(\mathrm{n}=398)(\%)\end{array}$ & $\begin{array}{l}p \text { Value } \\
\text { (Pearson } \chi^{2} \text { ) }\end{array}$ \\
\hline NSAP & $114(38.1)$ & $134(42.7)$ & $154(38.7)$ & 0.441 \\
\hline Appendicitis & $24(8.0)$ & $27(8.6)$ & $45(11.3)$ & 0.278 \\
\hline Pancreatitis & $41(13.7)$ & $26(8.3)$ & $34(8.5)$ & 0.038 \\
\hline Cholecystitis & $40(13.4)$ & $36(11.5)$ & $36(9.0)$ & 0.190 \\
\hline Biliary colic* & $35(11.7)$ & $28(8.9)$ & $28(7.0)$ & 0.103 \\
\hline Gastroenteritis & $1(0.3)$ & $2(0.6)$ & $9(2.3)$ & 0.037 \\
\hline Bowel obstruction & $4(1.3)$ & $9(2.9)$ & $16(4.0)$ & 0.110 \\
\hline Renal & $5(1.7)$ & $11(3.5)$ & $10(2.5)$ & 0.357 \\
\hline Gynaecology & $4(1.4)$ & $8(2.5)$ & $11(2.8)$ & 0.424 \\
\hline Upper GI inflammation† & $6(2.0)$ & $6(1.9)$ & $6(1.5)$ & 0.866 \\
\hline HPB malignancy & $5(1.7)$ & $5(1.6)$ & $10(2.5)$ & 0.615 \\
\hline Cholangitis & $3(1.0)$ & $2(0.6)$ & $7(1.8)$ & 0.367 \\
\hline Perforated viscus & $5(1.7)$ & $2(0.6)$ & $4(1.0)$ & 0.457 \\
\hline Constipation & $1(0.3)$ & $2(0.6)$ & $6(1.5)$ & 0.224 \\
\hline Respiratory & 0 & $1(0.3)$ & $3(0.8)$ & 0.282 \\
\hline Non-HPB malignancy & $2(0.7)$ & $5(1.6)$ & $3(0.8)$ & 0.426 \\
\hline Others & $9(3.0)$ & $10(3.2)$ & $16(4.0)$ & 0.731 \\
\hline Ischaemic colitis & 1 & 2 & 1 & \\
\hline Volvulus & 0 & 1 & 0 & \\
\hline Diverticular disease & 0 & 3 & 3 & \\
\hline Adenomyomatosis & 1 & 2 & 1 & \\
\hline Venous Thrombosis (SMV/PV) & 2 & 0 & 0 & \\
\hline Pancreatic Pseudocyst & 0 & 1 & 2 & \\
\hline Inflammatory Bowel & 0 & 0 & 2 & \\
\hline Lymphoma & 1 & 0 & 0 & \\
\hline Idiopathic biliary sepsis & 1 & 0 & 0 & \\
\hline Liver cyst & 1 & 0 & 0 & \\
\hline Cirrhosis & 1 & 0 & 0 & \\
\hline Fatty liver & 0 & 1 & 0 & \\
\hline Pseudo-obstruction & 0 & 0 & 1 & \\
\hline Mesenteric Adenitis & 0 & 0 & 1 & \\
\hline Stomal inflammation & 0 & 0 & 1 & \\
\hline Abdominal aortic aneurysm & 0 & 0 & 1 & \\
\hline Splenic capsule pain & 0 & 0 & 1 & \\
\hline Musculoskeletal & 0 & 0 & 1 & \\
\hline Postoperative site fluid collection/infection & 1 & 0 & 1 & \\
\hline
\end{tabular}

*Gallstone in gallbladder and/or common bile duct.

†Oesophagitis/gastritis/duodenitis.

Gl, gastrointestinal; NSAP, non-specific abdominal pain; HC, 'Hot Clinic'.

consultant surgeon sessions are required to cover the emergency theatre and allow the on-call consultant to be free to run the HC.

The electronic record system initially recorded all GP referrals as 'admitted' even if they were just seen and discharged in order to register them with the hospital electronic records, which in turn affected the accuracy of the recording of the proportion of patients being admitted in group 2. This was identified and a new recording system was put into place in the daily handover sheet. Therefore, the recorded proportion of patients being admitted in group 3 is a more representative indication of the impact of the HC. Group 2 was collected only 4 weeks after the commencement of the $\mathrm{HC}$, raising the possibility that not all the consultants involved in this study period were familiar with the processes around the HC. Because the study only included patients referred with acute abdominal pain, the impact of the HC is in that context. Expanding the context to include all ambulant emergency referrals (eg, postoperative wound problems and superficial abscesses) is likely to lead to additional benefit. Morbidity and mortality outcomes of patients after the introduction of the $\mathrm{HC}$ have not 


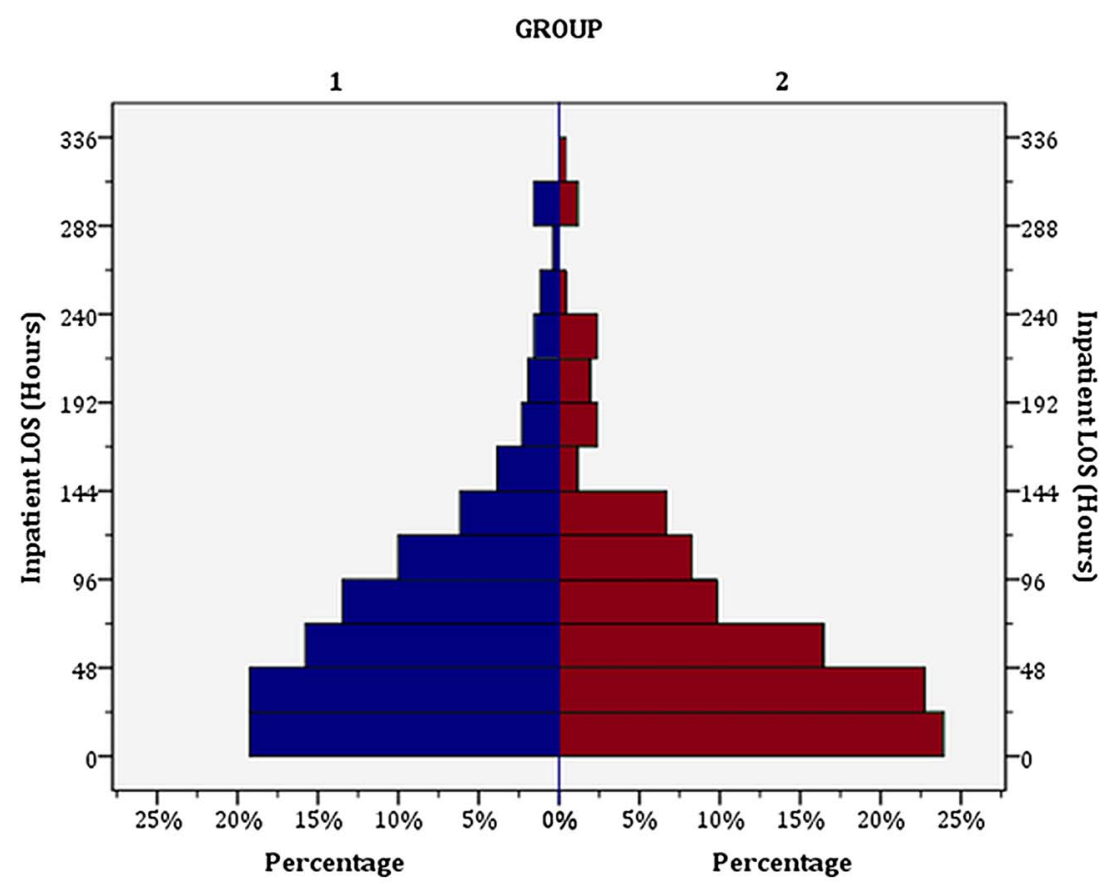

GROUP

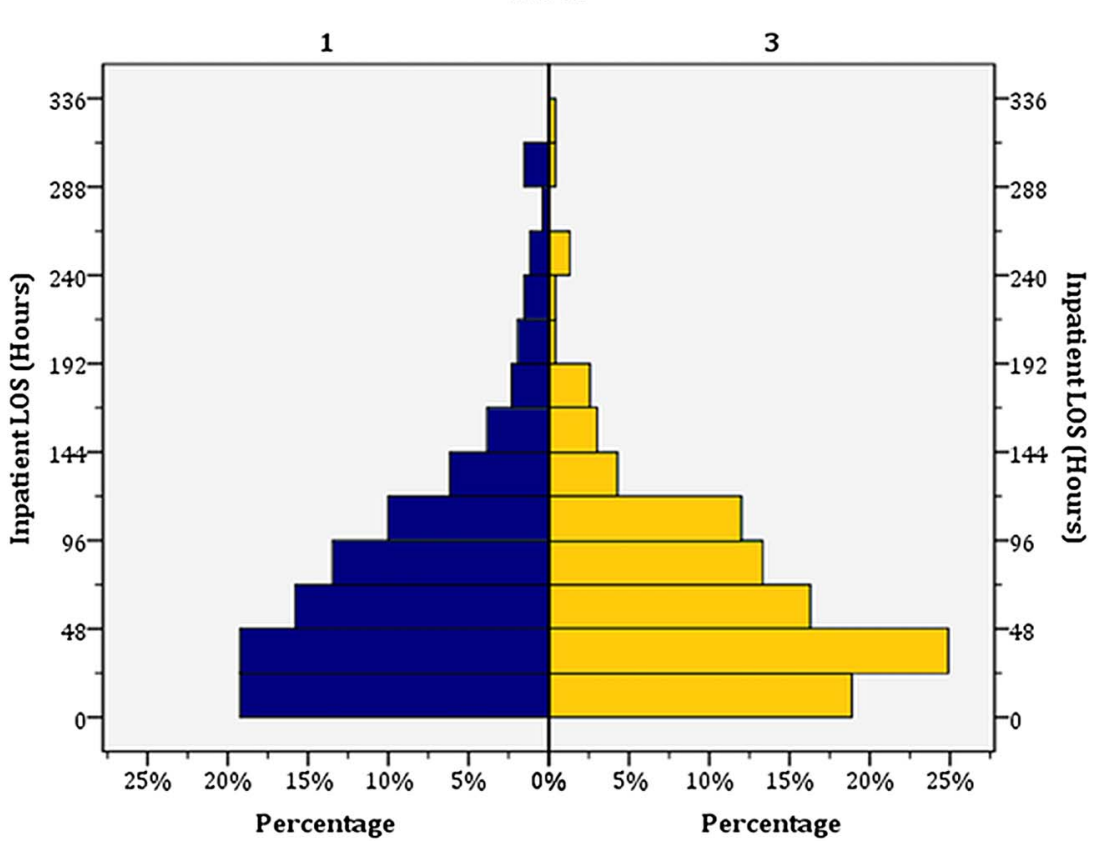

Figure 2 Inpatient length of stay. LOS, length of stay.

been evaluated in detail in this study. This analysis may further add weight to the validity of the HC.

\section{CONCLUSION}

The increasing number of patients referred to acute surgical services is driving innovation in service organisation. The HC enables senior surgeons to initiate investigation and management plans in selected patients who can be observed and further assessed in an outpatient fashion. The introduction of the HC was associated with a significant reduction in the proportion of patients presenting with acute abdominal pain who were admitted as inpatients and a reduction in the duration of inpatient hospital stay. This service redesign is likely to have profound implications for improving the patient experience in acute surgical care. The significant reduction in inpatient resources over the study period was realised with a relatively small increase in medical and nursing personnel. Future studies examining the impact of the HC should consider all ambulant general surgical referrals irrespective of the presenting symptoms. This study demonstrates that the HC represents a workable successful service redesign model. 
Key messages

What is already known on this subject?

- The General Surgical HC have shown to be of benefit in a few smaller sample sized studies.

What this study adds?

- This study is a larger sample-sized, prospective study with data analysed at different post-interventional stages demonstrating that the $\mathrm{HC}$ represent a workable successful service redesign model.

How it might impact on clinical practice in the foreseeable future?

- The introduction of a HC in surgical and medical specialities is likely to improve patient experience in an acute care setting, and to help the specialties adapt to the increasing demand on the NHS resources.

\section{Author affiliations}

${ }^{1}$ Department of Clinical Surgery, School of Clinical

Sciences and Community Health, The University of

Edinburgh, Edinburgh, UK

${ }^{2}$ St George's School, Edinburgh, UK

${ }^{3}$ General Surgery Department, Royal Infirmary of Edinburgh, NHS Lothian, Edinburgh, UK

Acknowledgements All authors express their gratitude for the support and assistance of all the surgical team members and ward staff and senior management for their support during this initiative. Alice Paterson-Brown was in receipt of a Nuffield Foundation Bursary.

Collaborators Members of the Edinburgh Emergency Surgery Study Group (Study Contributors): Graeme Couper, Chris Deans, Gavin GP Browning, Anna M Paisley, Bruce Tulloh, Richard JE Skipworth, Shona Mowitt, Alison Forsyth, Suzanne Crawford, Claire Leavy.

Contributors FT: acquired, analysed and interpreted data, drafted and revised paper and approved submitted version of study. C S: analysed data, revised paper and approved submitted version of study. A P-B: designed, acquired and analysed pilot study, interpreted data, revised paper and approved submitted version of study. R R: designed intervention, acquired and analysed pilot study, interpreted data, revised paper and approved submitted version of study. P L: designed study, interpreted data, revised paper and approved submitted version of study. A d B: interpreted data, revised paper and approved submitted version of study. $S$ P-B: suggested the introduction of the HC, designed study, interpreted data, revised paper and approved submitted version of study. D J M: designed study, interpreted data, drafted and revised paper, and approved submitted version of study.

Competing interests None declared.

Ethics approval South East Scotland Research Ethics Service of National Health Service (NHS) Lothian.

Provenance and peer review Not commissioned; externally peer reviewed.

Data sharing statement Patient data used in the study are available on the national electronic archive system - national electronic patient record (TRAK) System, and are available to personnel who have been given authorisation by NHS to access TRAK.

\section{REFERENCES}

1 Royal College of Surgeons and Association of Surgeons of Great Britain and Ireland. Commissioning guide: Emergency general surgery (acute abdominal pain), 2014.
2 Chang CC, Wang SS. Acute abdominal pain in the elderly. Int J Gerontol 2007;1:77-82.

3 Gans SL, Pols MA, Stoker J, et al. expert steering group. Guideline for the diagnostic pathway in patients with acute abdominal pain. Dig Surg 2015;32:23-31.

4 University of Leeds \& Media Innovations Ltd. Computer aided diagnosis of Acute Abdominal Pain from the Clinical Information Science Unit. http://www.aaphelp.leeds.ac.uk/ aaphelp/background.asp (accessed 26 May 2015).

5 iSD Scotland, NHS National Services Scotland (2014). Annual information by specialty (Episodes, Stays and Patients)-NHS Board of Residence. [Excel document]. Under Summary Statistics, in Inpatient and Day Case Activity (accessed 13 May 2015).

6 Ambulatory Emergency Care, NHS Elect. Case Studies. [World Wide Webpage]. 2013. http://www.ambulatoryemergencycare. org.uk/News/Case-Studies (accessed 26 May 2015).

7 Dr David Staples, Derby Hospitals NHS Foundation Trust. Consultation led phone triage as part of an integrated Ambulatory Care model. [PDF document]. 2012. https://www. rcplondon.ac.uk/sites/default/files/05_-_david_staples.pdf (accessed 26 May 2015).

8 Standardisation Committee for Care Information. Ambulatory Emergency Care Standard-Statement of Need. 2014. http:// www.england.nhs.uk/iscg/wp-content/uploads/sites/4/2014/11/ 20141029_SCCI_Item_5_1_I2N-5644-SCCI2027-AmbulatoryEmergency-Care-SoN-v011.pdf (accessed 26 May 2015).

9 The Royal Wolverhamptom NHS Trust. City community services: Alcohol Strategy-Community based alcohol services consultation. 2015. http://www.royalwolverhamptonhospitals. nhs.uk/city_community_services/healthy_city/alcohol_strategy/ community_based_alcohol_servic.aspx (accessed 26 May 2015).

10 NHS Brent Clinical Commissioning Group. Gynae consultation. 2015. http://brentccg.nhs.uk/en/ gynaecology-consultation (accessed 26 May 2015).

11 NHS England. Enhancing the quality of life for people with long term conditions-The House of Care. 2015. http://www. england.nhs.uk/house-of-care/ (accessed 26 May 2015).

12 NHS Lothian. Developing person-centred primary and community services. Our Health, Our Care, Out FutureAppendix 3. (PDF document). 2014. http://www.nhslothian. scot.nhs.uk/OurOrganisation/OurHealthOurCareOurFuture/ SupportingDocuments/OurHealthOurCareOurFuture/ Appendix\%203\%20-\%20Developing\%20Person\%20Centred\% 20Primary\%20and\%20Community\%20Services.pdf (accessed 26 May 2015).

13 Javed M, Hall B, Young S, et al. Is 'hot clinic' a 'hot' idea for evaluating emergency surgical admissions?. Int J Surg 2011;9:529-30.

14 Shatkar V, Imtiaz M, Wain M, et al. Surgical 'Hot Clinics': What do the patients think?. World J Surg Res 2015;4.

15 Audit Scotland. Accident and Emergency performance update, Auditor General. [PDF document]. 2014. http://www.auditscotland.gov.uk/docs/health/2014/nr_140508_ae_update.pdf (accessed 26 May 2015).

16 Campbell WB, Lee EJK, Van de Sijpe K, et al. A 25 -year study of emergency surgical admissions. Ann R Coll Surg Engl 2002;84:273.

17 Capewell S. The continuing rise in emergency admissions. BMJ 1996;312:991-2.

18 Chezhian C, Pye J, Jenkinson LR. The next millennium--are we becoming emergency surgeons? A seven year audit of 
surgical and urological admissions in a rural district general hospital. Ann R Coll Surg Engl 2001;83:117.

19 Al-Mulhim AA. Emergency general surgical admissions. Prospective institutional experience in non-traumatic acute abdomen: implications for education, training and service. Saudi Med J 2006;27:1674-9.

20 Kirkegaard HT, Olesen F. [Elderly people admitted to hospital for social reasons. Patients' and their networks' perceptions of problems and expectations prior to the admission]. Ugeskr Laeger 2000;162:4254-7.

21 Irvin TT. Abdominal pain: a surgical audit of 1190 emergency admissions. Br J Surg 1989;76:1121-5. http://dx.doi.org/10. 1002/bjs. 1800761105

22 Hawthorn IE. Abdominal pain as a cause of acute admission to hospital. J R Coll Surg Edinb 1992; 37:389-93. 